\title{
ANALYSING UNSUCCESSFUL EXPERIMENTS AND INSTRUMENTS WITH THE REPLICATION METHOD
}

\author{
P. HEERING \\ Universitat Oldenburg
}

ABSTRACT: The aim of this paper is to discuss instruments and experiments from the history of physics that were rejected in the historical situation. As a consequence, only very few of these devices were produced - and virtually none of them did survive. Thus, in order to develop an understanding of the experimental practice connected with these devices the replication method is applied. In short, this method- which will be discussed on a general level in the first part of the paper - is based on self-reflexive interaction with reconstructed apparatus and the contextualisation of the experiences made in the laboratory. The example of experiments published by Jean Paul Marat in the 1780ies shall illustrate the usefulness of this method in order to develop an understanding of experiments that were rejected in the historical situation.

\section{Foreword}

The aim of this paper is twofold: I am going to discuss instruments (and the experiments connected with these devices) that were neither produced in large numbers nor were accepted in their historical context. An analysis of these 'unsuccessful' experiments and apparatus seems to be relevant for the history of science although they did not get very much attention yet. In this paper I will discuss two case studies that were carried out with the replication method which has been developed and used by historians of science in Oldenburg for some twenty years ${ }^{1}$. In this respect the paper also aims to give an introduction into this approach,

${ }^{1}$ Although this method is connected with the Oldenburg group it has some precursors. The earliest attempts to use the experiences made in redoing historical experiments had been 
therefore the case studies shall also serve as an illustration of this method. Consequently I will discuss in the first part of my paper some general aspects of unsuccessful experiments and give a more general introduction and description of the replication method. In the second part I am going to discuss a case study on 'unsuccessful' experiments that has been prepared with this approach.

\section{Unsuccessful experiments and their historiographical analysis}

Until the 1980s traditional accounts in the history of science could have been characterised by two aspects: they were strongly focused on theories, most of them completely ignored the role of experiments in the process of producing scientific knowledge. And they focused on 'heroes', successful scientists whose names could be related to major achievements in the development of scientific knowledge $^{2}$. Nowadays, these accounts are no longer 'state of the art',

described by Thomas Settle who analysed some of Galilei's experiments, besides his work and other case studies on Galilei are particularly those of David Gooding to be mentioned, see Thomas B. SETTLE: 'An Experiment in the History of Science', Science 133, pp. 19-23 and DAVID GoODING: 'History in the Laboratory: Can we tell what really went on?', in Frank A.J.L. James (ed.): The Development of the Laboratory (London; 1989), pp. 63-82.

For a more detailed discussion of the replication method see Peter HEERING, Das Grundgesetz der Elektrostatik: Experimentelle Replikation und wissenschaftshistorische Analyse (Wiesbaden, 1998), Christian SICHAU: 'Die Replikationsmethode: Zur Rekonstruktion historischer Experimente', in P. HeERING, F. RiEß, C. SiCHAU (eds.), Im Labor der Physikgeschichte, (Oldenburg, 2000), pp. 9-70, and idem: Die Viskositätsexperimente von J.C. Maxwell und O.E. Meyer: Eine wissenschaftshistorische Studie über die Entstehung, Messung und Verwendung einer physikalischen Größe (Berlin 2002). For some case studies that are based on this method see P. HEERING, F. RIEß, C. SICHAU (eds.), Im Labor der Physikgeschichte, (Oldenburg 2000), see also Jan FrERCKS: 'Creativity and Technology in Experimentation: Fizeau's Terrestrial Determination of the Speed of Light', Centaurus 42 (2000), pp. 249-287; Peter HeERING: 'On Coulomb's Inverse Square Law', American Journal of Physics 60 (1992), pp. 988-996; Jochen HENNING: Der Spektralapparat Kirchhoffs und Bunsens, (München 2003), HeINZ OTTO SiBUM: Reworking the Mechanical Value of Heat: Instruments of Precision and Gestures of Accuracy in Early Victorian England, Studies in the History and Philosophy of Science 26 (1995), pp. 73 - 106, Christian SiCHAU: 'Die Joule-Thomson-Experimente - Anmerkungen zur Materialität eines Experiments', NTM 8 (2000), pp. 223-243; Adelheid Voskuhl: 'Recreating Herschel's actinometry: An essay in the historiography of experimental practice', British Journal for the History of Science 30 (1997), pp. 337-355; Roland WITTJE: 'Heinrich Hertz und die Einbettung von experimenteller Tärigkeit in theoretische Konzepte', in Christoph MEINEL (ed): Instrument Experiment: historische Studien, (Berlin, Diepholz 2000), pp. 180-191.

${ }^{2}$ This is of course an oversimplification as some historians and philosophers of science such as Paul Feyerabend or John Desmond Bernal published differentiated accounts of the development of scientific knowledge. 
experiments have become a major issue in analysing the development of science. Moreover, it is no longer only the scientists themselves but also instrument makers and laboratory assistants who have gained significant attention. However, one aspect in the historiography that still seems to be underrepresented are those researchers who failed to gain scientific reputation by their contemporaries, whose experiments and theories were rejected or, maybe even worse, ignored ${ }^{3}$. Thus it seems desirable to expand the analysis of the history of science in this direction. Before this claim is going to be justified, a clarification seems to be necessary in respect to characterise what is going to be considered as being an unsuccessful experiment ${ }^{4}$.

To simplify things I am going to discuss in this paper only those experiments that had been published, and certainly not every experiment gets published particularly not those the experimenter himself or herself decided to be a failure and consequently did not write a paper. In order to distinguish these experiments from those I am going to discuss I am using the term 'unsuccessful experiment' instead of using the concept of 'failure'.

It should be made clear that the criterion of an unsuccessful experiment could not be the acceptance in terms of the modern scientific knowledge. Instead I am suggesting to use the historical reaction to the publication as a criterion. If an experiment was strongly criticised or ignored and thus was not considered to contribute anything to the scientific knowledge in the historical situation I consider this as an unsuccessful experiment. To illustrate this with an example: Contrary to the experiments I am going to discuss in the following the one described by Paul Louis Simon in 1808 as an attempt to overthrow Coulomb's law in electrostatics would be taken to be unsuccessful from the modern point of view. However, in the historical situation it became successful as it was widely discussed in Germany and also included in several textbooks 5 .

${ }^{3}$ I am indebted to Michael Barth who pointed out in a paper presented at the 1993 'DPG history of physics section' meeting in Mainz that being ignored could be an even stronger form of rejection than open refutation.

${ }^{4}$ It is not possible in this paper to give a complete definition or discussion of what might be considered as being an unsuccessful experiment. However, some clarifications in order to avoid misunderstandings seem to be necessary.

5 Paul Louis SIMON: "Ueber die Gesetze, welche dem electrischen Abstoßen zum Grunde liegen", Annalen der Physik 28 (1808), pp. 277-298. For an analysis of this experiment see Peter Heering: 'The replication of the torsion balance experiment: The inverse square Law and its 
This description of unsuccessful experiments leads to several difficulties: As these experiments were neither discussed nor repeated by contemporary researchers the information we have is not as detailed as in the case of experiments that were successful. Moreover, unsuccessful experiments are in most cases not as compatible to our conceptions as the successful ones. Thus it is very difficult to develop an idea of the way these experiments were to be performed and what was to be observed. Despite these difficulties it seems to be necessary to develop a better understanding of these experiments for at least two reasons: First of all it seems to be necessary to come to a symmetrical account of unsuccessful and successful experiments ${ }^{6}$. Only when both are treated in the case studies in a symmetrical manner we are able to get a picture of scientific progress that is not arguing retrospectively but can analyse historical arguments and develop an understanding why certain experiments and the findings connected with these experiments were accepted whilst others were rejected. This seems particularly important as the criteria for the acceptance or rejection are not invariant. Therefore it would be anachronistic to apply our modern criteria in respect to the analysis of a historical situation.

One possible approach to develop a better understanding of these experiments could be provided by applying the replication method on these experiments.

\section{The replication method in the historiography of science}

To simplify things the replication method can be described as being composed of three phases: The reconstruction of an apparatus, the redoing of an experiment and the contextualisation of the experiences made in the first two

refutation by early 19th-century German physicists', in Christine BLONDEL \& Matthias DORRIES (eds.): Restaging Coulomb: Usages, Controverses et réplications autour de la balance de torsion (Firenze 1994), pp. 47 - 66 and Eric MENDOZA: 'The Electrostatic Beam Balance and its Use in Determining the Law of Repulsion between Charges, 1808-1825, Archives Internationales d'Histoire des Sciences 50 (2000), pp.296-301.

6 This symmetrical approach has been strongly advocated by David Bloor, however, as Frercks has observed, this approach is mainly applied in order to discuss successful experiments, see Jan FRERCKS: Die Forschungspraxis Hippolyte Fizeaus: Eine Charakterisierung ausgebend von der Replikation seines Atherwindexperiments von 1852 (Berlin 2001). As a discussion that can be considered as being exemplary in respect to the symmetrical approach see Oliver Hochadel: Offentliche Wissenschaft: Elektrizität in der deutschen Aufklärung (Göttingen 2003). 
phases. All three phases as well as their relationship need some further explanation in order to reduce the simplification.

To reconstruct the apparatus means to build a device that corresponds as close as possible to all the information given by the sources. Sources are not only the original publication but could also be laboratory notebooks, manuscripts, letters, and instruments that have survived e.g. in museums or university collections. Based on all information the reconstruction of the set-up is carried out. However, even if several sources are available the information provided will not be complete in respect to every detail of the set-up: Papers as well as laboratory notes were never written with the intention to give a complete and time-independent account of the set-up. Normally many aspects were considered as irrelevant or self-evident and thus omitted, such as the question how materials are joined, what was used as a coating, what specific type of stand had been used etc. Even if the instrument has survived it is not clear whether it remained unchanged, and that does not only refer to changes which were carried our for various reasons by some curator but also the experimenter himself may have changed parts of the set-up in order to use the device in other experiments. Moreover, instruments are not timeless, some materials change during the decades, consequently a set-up kept in a museum would not in every case fit the criteria that are employed for the reconstructed set-up. Furthermore, like in the case of the written accounts, also collections normally contain in most cases only the 'central unit' of a set-up, peripheral devices were in most cases not considered to be collectibles and thus destroyed or lost?

Reconstructing the device is not an end in itself but the aim is to redo the experiments with the reconstructed devices. On the first look this may produce the image of replicating an experiment in the sense Harry Collins had given to this term $^{8}$. However, there are two distinctions that are significant for the replication method in the historiography of science: The experiments are not conducted in order to check the initial result but in order to develop a better understanding of the necessary skills and general conditions of the experiment. Thus, the experiment is -contrary to a purely scientific experiment- carried

7 The problem of set-ups being not stable in time as well as the focus of instrument collections on 'central devices' is discussed in SICHAU: Viskositätsexperimente (ref. 1).

${ }^{8}$ Harry Collins: Changing Order: Replication and Induction in Scientific Practice. Second Edition, with a new Afterword (Chicago 1992). 
out according to the historical description and it is conducted in a self-reflexive manner'. This means that the experimenter is observing his or her own behaviour, how he or she is adjusting the own actions to the experimental set-up and what kind of skills are to be developed in order to perform the experiment properly. This description may produce the picture that the data are irrelevant and that the procedure in the laboratory is only a "trial operation" ${ }^{10}$. Such an interpretation misses a central aspect in respect to the work done in the laboratory: It is to be attempted to make a connection between the own experimental activity and the historical experiment. This seems to be self-evident as the intention of the replication method is to develop an understanding how the initial experimenter may have been able to produce his or her results. However, to consider the data produced and their consistency with the originally published data being crucial for the relevance of the experiences made in the laboratory would also be misleading ${ }^{11}$. In some cases it was not possible to reproduce the data (exactly), however, the reason for this failure offered insights for the historical case study.

The experiences made in the first two phases are to be contextualised in the third phase, they are to be placed in a broader historical as well as philosophical, cultural, social, technological or political context. In this respect it seems to me particularly important to stress the notion that the experiment itself and the experiences made are not to be considered as a source like a manuscript or a surviving instrument. In most cases, the outcome of the first two phases can more accurately be described either as a focal shift or as an inconsistence with the interpretation of the experiment as it was made up from the traditional analysis. In any of these cases the third phase requires a different viewpoint in looking at the traditional source materials. This may also imply to consider material that had hitherto not been considered as being relevant for the historiographical

${ }^{9}$ In this respect Frercks is an exception as he claims in particular that he is working like a physicist with his set-up, see FrERCKS (ref. 6).

10 H. Otro SibuM: ,Die Sprache der Instrumente. Eine Studie zur Praxis und Repräsentation des Experimentierens', in HeIDELBERGER, Michael; STEINLE, Friedrich (eds.): Experimental Essays - Versuche zum Experiment (Baden-Baden 1998), pp. 141- 156, on 142. For a criticism of Sibum's description see FrERCKS (note 6),

${ }^{11}$ This seems to be the position held by Maria Trumpler when she argued: “The only test to see if you have in fact reconstructed what [the original researchers] have done is if you get the data they get", in Steven Dickman: 'Could Coulomb's Experiment Result in Coulomb's Law?', Science 262 (1993), pp. 500-501, on 501. 
analysis of the experiment. Providing a reason and producing a point of origin for this different analysis of the traditional source material seems to be one of the strengths of the replication method.

Although I have divided the replication method into three phases it has to be understood that this is only possible for analytical purposes. In applying this method all three phases are closely interwoven and cannot be separated. When the reconstruction is planned the contextualisation is already taking place as specific questions arise on how and from which materials the set-up has to be built. Likewise, in most cases the set-up is not completely finished when the experimenting starts but the apparatus needs some kind of debugging in order to work properly. Moreover, in some of the experiments the initial work with the apparatus showed that the information gathered from the sources were incorrect - or incorrectly interpreted.

This brief introduction of the replication method may suffice to give a sufficient methodological background to the following case study which is intended to show the utility as well as the difficulties one may encounter in analysing unsuccessful experiments with the replication method. It focuses on experiments described by Jean Paul Marat in the 1780ies which were immediately rejected by most French scientists and in particular by the Paris Academy of Sciences.

\section{Jean Paul Marat and his experiments on optics and electricity}

Jean Paul Marat is typically known for his role during the French Revolution. However, before becoming a political journalist he attempted unsuccessfully to establish himself as a natural philosopher. This attempt became obvious in 1779 when Marat published his first monograph in the field of natural philosophy ${ }^{12}$. Through the Comte de Maillebois he submitted this memoir to the Paris Académie Royale des Sciences, the most eminent institution and ultimate scientific authority in France, requesting a report on it. The Academy asked de Maillebois, de Montigny, Le Roy and Sage to prepare the report which was read on April $25^{\text {th }}, 1779$. Over all the report was positive with the experiments rated to

12 Jean Paul MARAT, Découvertes sur le Feu, l'Électricité et la Lumierre, constatées par une Suite d'Expériences nouvelles qui viennent d'être vérifiées par MM. Les Commissaires de l'Académie des Sciences, $2^{\text {nd }}$ Edition (Paris, 1779). 
be "new, accurate, and carried out in a manner as well ingenious as proper" ${ }^{13}$. Although the commission stated that they -in accordance with Marat's specific wish-did not referee the theory included in the publication this report could be considered as being a first successful step towards a career in natural philosophy.

Consequently, Marat rushed to present his next monograph ${ }^{14}$ to the Academy, asking for another report. Again a committee was charged with its preparation, this time however things did not go so smoothly. After several months the report had still not been read in the Academy. Therefore, Marat began to put pressure on Jean Baptiste Le Roy, the member of the committee responsible for the report, demanding the same finally be finished. As these efforts turned out to be fruitless, Marat began to write notes to Condorcet requesting him to arrange the publication of the report, these attempts also in vain ${ }^{15}$. The report was finally read on May $10^{\text {th }}, 1780$ and probably turned Marat's impatience into frustration as the report was negative. The experiments "appeared not to prove what the author imagines that they prove, and because they are in general contrary to the most familiar parts of optics, we believe it would be useless to enter into the great detail that would be necessary to explain them" ${ }^{16}$. Consequently, the Academy refused to give their approbation to Marat's publication.

Despite this discouraging report, Marat decided to publish his monograph and an additional one on heat which also appeared in print in $1780^{17}$. When first glancing through these three publications two aspects in particular are striking: each of the three works contains more than one hundred experiments; and most of these experiments are carried out with the same instrument: a device that Marat claimed to have developed himself and which he named the helioscope.

${ }^{13}$ Marat reproduced this report as a preface to his memoir, see MARAT, Découvertes (note 12).

${ }^{14}$ Jean Paul MARAT, Découvertes sur la Lumière; constatées par une suite d'expériences nouvelles: qui ont faites un très-grand nombre de fois sous les yeux de MM. les Commissaires de l'Académie des Sciences (London \& Paris, 1780).

15 Some of the letters are reprinted in Charles Vellay (ed.), La Correspondance de Marat, (Paris 1908), pp. 7f. and pp..58-64.

${ }^{16}$ The report of the committee can be found in MARAT, Lumiere (see note 14), the quotation is translated in Thomas L. HANKINS; Robert J. SILVERMAN, Instruments and the Imagination (Princeton (NJ), 1995), p. 60. The report refers to Marat's new explanation of the diffraction of white light that contradicted Newton's theory. This aspect is discussed in detail in Charles Coulston GILLISPIE, Science and Polity in France at the End of the old Regime (Princeton (NJ), 1980).

${ }^{17}$ Both monographs as well as the 1782 monograph on electricity were translated into German by the Greifswald chemistry professor Christian Ehrenfried Weigel. 


\section{The helioscope}

In basic terms the helioscope can be described as a modified standard device of the second half of the eighteenth century: The solar microscope which is ascribed to Nathaniel Lieberkühn; he gave a first account of the instrument in $1739^{18}$. The instrument became quickly very popular and could be found in most catalogues of instrument makers such as George Adams, Benjamin Martin, and Edward Nairne. They offered several different types of this device, at a cost from $£ 5$ to $£ 21^{19}$. The solar microscope was used in a darkened room in order to demonstrate magnified objects to an audience (see Fig. 1).

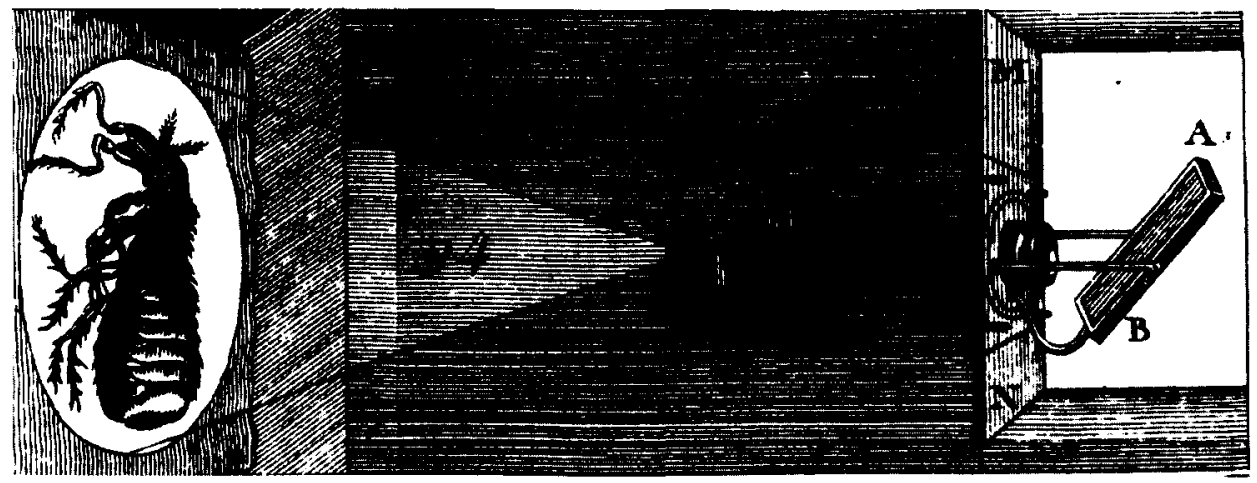

Fig. 1: Solar microscope. Table from Francois Para du Phanjas, Théorie des Etres Sensibles ou Cours Complet de Physique, spéculative, Expérimentale, Systématique et Gémétrique, 3 (Paris 1773), courtesy of the Bakken Library Minneapolis, MN.

${ }^{18}$ See HaNkIns/SilverMan, Instruments (note 16); E.H. SCHMITZ, Handbuch der Geschichte der Optik: Das Mikroskop. 2. Ergänzungsband, Teil A (Bonn, 1989) p. 343.

${ }_{19}$ On the development of the solar microscope see SCHMITZ, Handbuch (note 18), pp.343351; and idem., Handbuch der Geschichte der Optik: Von Newton bis Fraunhofer (Bonn, 1982), 371-375. On the prices of solar microscopes in the last decades of the $18^{\text {th }}$ century see George ADAMS, An essay on electricity; in which the theory and practice of that useful science, are illustrated by a variety of experiments, arranged in a methodical manner, (1st ed., London, 1784). A comparable price range can also be found in the 1799 catalogue when W. and S. Jones had taken over the workshop, though they offered a wider variety of instruments, see George ADAMS, An essay on electricity; explaining the theory and practice of that useful science; and describing the Instruments, contrived either to illustrate the theory, or render the practice entertaining, edited and with additions by William Jones (5th ed., London, 1799). This price range seemed to be a standard, as solar microscopes were offered by other instrument makers at comparable prices; see i.e. Edward NAIRNE, The description and use of Nairne's patent electrical machine; with the addition of some philosophical experiments and medical observations (London, 1783). 
Principally the instrument (see Fig. 2) consists of a mirror $A B$, a condensing lens with a focal length of some $200 \mathrm{~mm}$ and a so-called Wilson pocket microscope. The instrument was placed into the window shutter NO. The mirror and the lens are used to take the sunlight as a light source for the microscope. With the help of two screws, a toothed wheel and a toothed rack the mirror could be adjusted from the inside in order to compensate the (apparent) movement of the sun. The image of the object was projected onto a white screen ${ }^{20}$.

N
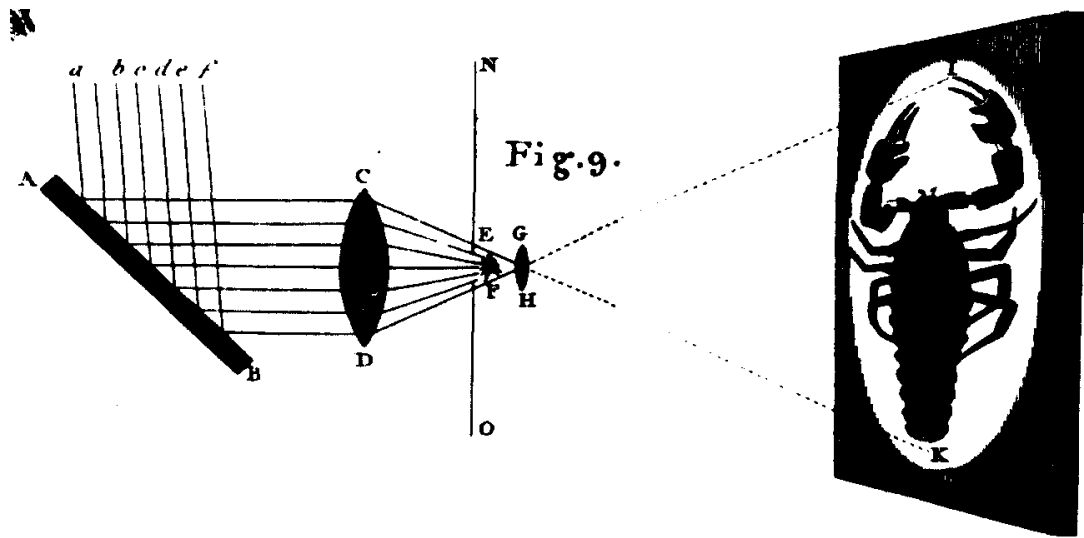

Fig. 2: Working principle of the solar microscope. Plate from George Adams, Lectures on Natural and Experimental Philosophy (London 1794), courtesy of the Bakken Library Minneapolis, MN.

In transforming the solar microscope into his helioscope Marat removed the Wilson pocket microscope. The resulting device basically produced a light cone into the darkened chamber. In some of the first experiments he described Marat placed heated objects into the light cone and claimed to have made visible the "fluide igné" (as he named it) emanating from heated bodies ${ }^{21}$. According to

${ }^{20}$ This screen can be taken as being one of the objects that has not received very much attention yet (a more general discussion of this 'neglect of peripheral devices' has been made by Christian Sichau: 'Industry and Industrial Relations within the Laboratory: The Material Conditions of Joule-Thomson Experiments', in Lette, MiCHEL; Oris, MiCHEL (Eds.): Proceedings of the XXth International Congress of History of Science 7: Technology and Engineering (Turnhout, Belgium, 2000, pp. 49-59). As Sichau discussed this problem in respect to a case study analysing a highly successful experiment the question of the role of peripheral devices is not limited to unsuccessful experiments. Therefore, it may be sufficient to simply mention that we reconstructed a screen according to Marat's description.

21 The modern interpretation of these shadow projections would be the refraction of the light by the hot air having a different density. 
Hankins and Silverman Marat used this device «for the first time as a research instrument ${ }^{22}$. This is certainly correct but I think it necessary to go one step further: Actually the helioscope is no longer a solar microscope but a new device with new qualities. It produces an environment that enabled Marat to carry out new experiments that were hitherto not possible, experiments that were designed to visualize the effects of manipulating the 'fluide igne' (see Fig. 3) ${ }^{23}$.

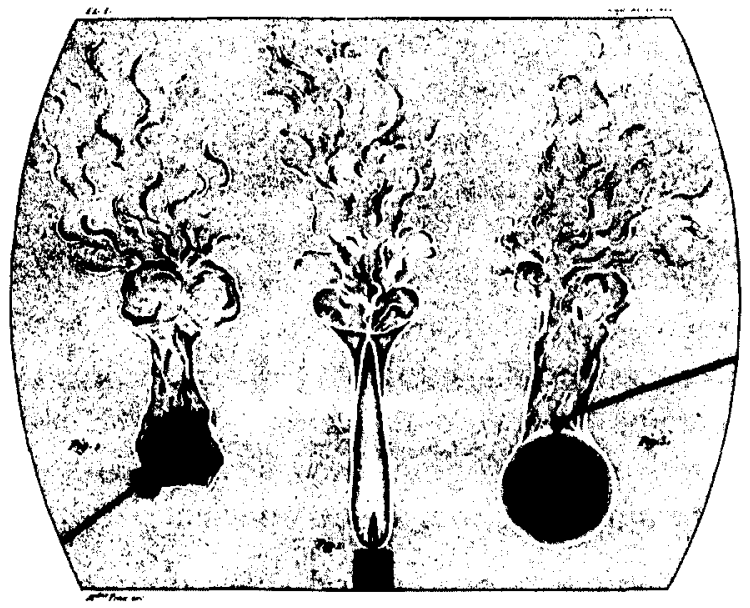

Fig. 3: Representation of the shadow projection of a glowing piece of charcoal (left), a burning candle (middle) and a hot metal ball (right). Plate published in Jean Paul Marat, Recherches physiques sue le Feu (Paris, 1780), courtesy of the Bakken Library Minneapolis, MN

In his publication Marat did not describe the helioscope in great detail, most likely because it did not seem to be necessary for his purposes. He stated explicitly that he was not giving a description of his apparatus as "the whole equipment could be found at Sikes (Opticien du Roi, place du Palais Royal à Paris) ....) ${ }^{24}$. Moreover, Marat was one of the public demonstrators who showed his experiments to a broader audience. Therefore, he might have used his demonstrations as another way of promoting his experiments and the instruments necessary to redo them.

22 HANKINS/SilverMaN, Instruments (note 16), p. 59.

${ }^{23}$ This image taken from Marat's publication on heat showed (from left to right) the shadow projection of a piece of charcoal, a burning candle and a hot metal sphere.

${ }^{24}$ Jean Paul MaraT, Recherches physiques sue ke Feu (Paris, 1780), p. 197. This interpretation is supported "by the fact that 'Sikes' (= Sykes), ..., was a retailer who specialized in the import of English instruments into France", A.J. TURNER, 'Jean Paul Marat's Helioscope', Bulletin of the Scientific Instrument Society 75 (2000), 34. 
Although it is not clear exactly which instrument served as a basis for Marat's helioscope, it seems to be reasonable to use as a basis for the reconstruction a solar microscope which is kept at the Universiteitsmuseum Utrecht ${ }^{25}$. This device had been made by the London instrument maker Benjamin Martin in the late 1770ies or early 1780ies and corresponds to all the information given in Marat's text. Moreover, the instrument is very much alike a device which is nowadays kept at the CNAM and that had been used by one of Marat's rivals, Jacques-Alexandre-César Charles $^{26}$. We did not attempt to reconstruct the complete solar microscope only those parts that form the helioscope. Consequently, we took only those measures that were necessary to build a helioscope, except for the lenses where we relied on the specifications already determined by Jan Deiman.

I am not going to discuss the reconstruction of the instrument which was carried out in the workshops of the university. For the device (see Fig. 4) only some measures were to be altered slightly, i.e. the screw thread had to be manufactured according to metric standards. Only the toothed wheel was purchased, a lens with the exact geometrical and optical specifications of the original one could be purchased from a local optician.

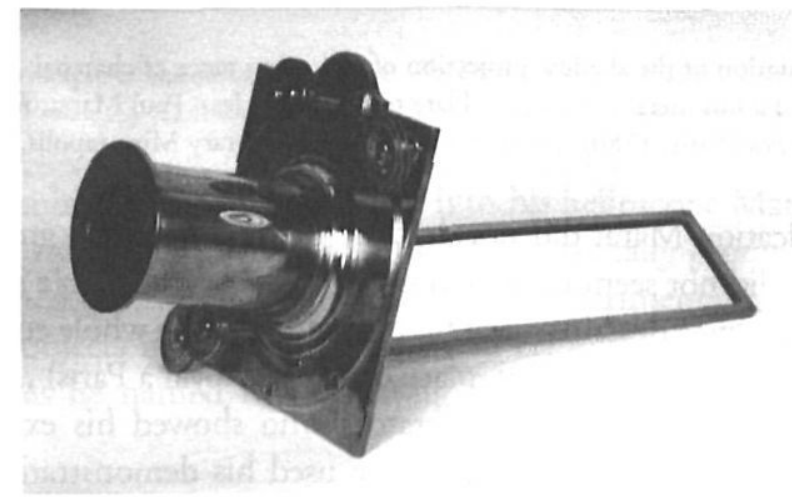

Fig. 4: Reconstruction of the helioscope. Photo W. Golletz.

${ }^{25}$ This instrument has the inventory number UM 386. On some of the microscopes kept at the Utrecht museum see J.C. Deiman: 'Utrecht University and its Microscopes', in: R.G.W. Anderson; J.A. BenneT; W.F. Ryan (Eds.): Making Instruments Count (Aldershot, 1993), pp. $329-340$.

26 This instrument was made by Dollond, another London instrument maker and is reproduced on the front cover of Jean-François Lemaire; Jean Pierre POIRIER (eds.), Marat homme de science? (Paris, 1993), however, it is wrongly attributed to Marat. 
The instrument was used in a modern laboratory, its windows were closed with a wooden shield in which the helioscope was placed. The light cone produced in the room ( see Fig. 5) was sufficient to give an illumination that made it possible to work without any other light source.

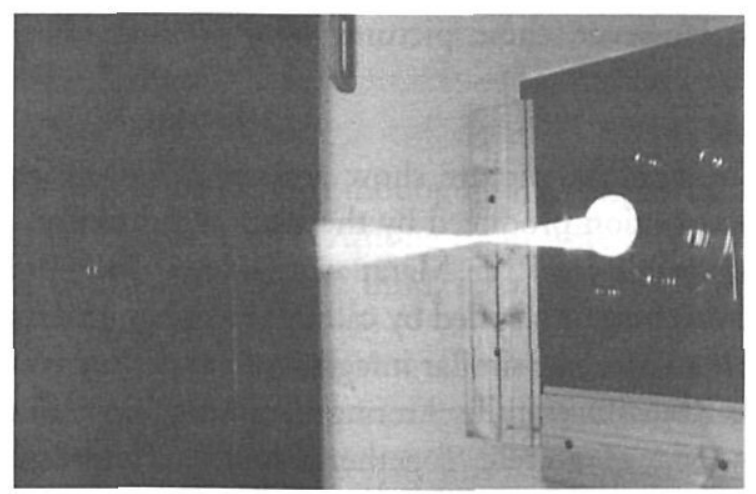

Fig. 5: Using the reconstruction of the helioscope, produced light cone. Photo S. Woltzen.

At first it was attempted to produce a circle of light onto the screen. This turned out to be easy, however it became also clear that the mirror had to be readjusted every five minutes when the light circle initially observable had turned into an ellipse. After practising a while it was possible to carry out the readjustment within a few seconds.

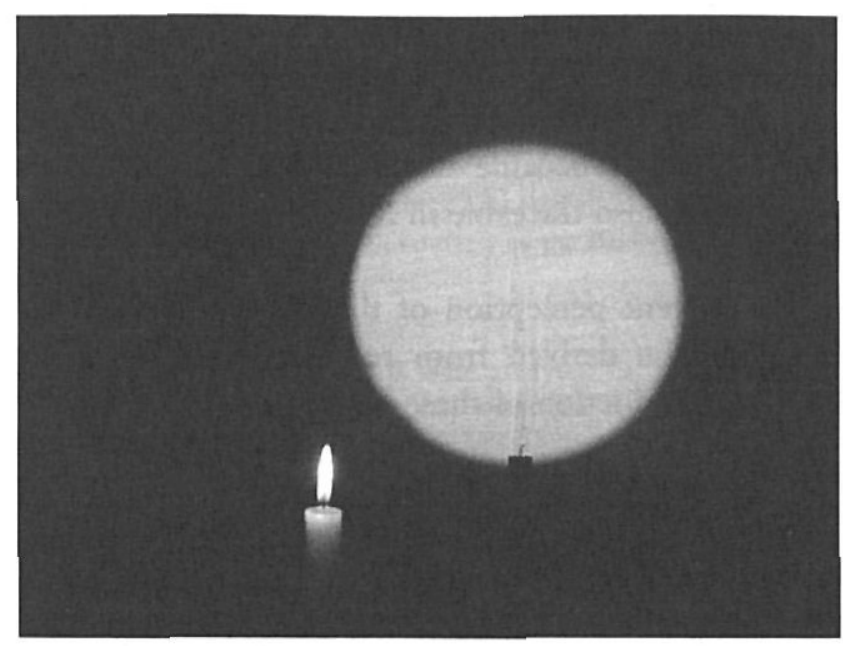

Fig. 6: Shadow projection of a burning candle. Photo P. Heering 
In a first series of experiments hot objects such as a burning candle (see Fig. 6) or a red hot metal ball were placed into the light cone. They had to be placed at a specific point into this light cone to produce a clear image on the screen, however, this position could easily be found out through trial and error. It was even possible to prepare photographic images, thus documenting the results of the experiments. However, these pictures were as misleading as was Marat's copperplate.

Both the plate and the picture show a static situation, this is completely different to the impression produced by the shadow projection. The appearance of the emanating 'fluide igne', as Marat would have described it, is changing permanently and can best be labelled by calling it a dynamic situation. Moreover, it was also possible to produce similar images from experiments with objects that were not as hot as a burning candle. Among these experiences was one which was not described by Marat himself. Together with the commission of the Paris' Academy of Sciences Benjamin Franklin had been visiting Marat's laboratory and tried his experiments. In the course of the experimentation it was also tried whether the 'fluide igne' was emanating from Franklin's almost bold head - it was $^{27}$. Likewise, it was possible to produce similar images on the screen with persons being placed with their head into the light cone. This was even more impressive as the silhouette of the head itself was identifiable on the screen and thus gave the image a personal note. But again the situation was not static but dynamic, the shadow projection of the 'fluide igne' produced the image that the fluid was emanating from the head in an upwards direction ${ }^{28}$. The dynamic is an aspect of these experiments that could be traced retrospectively in Marat's writings. Having seen the shadow projections and the dominant impression of the moving 'fluide igne' it became obvious that the rhetoric of permanent movement and change is also traceable in Marat's writings.

However, this different perception of the shadow projections was not the only result that could be derived from redoing Marat's experiments. It also became clear that the production of these images was not very difficult. Neither

27 This incident is mentioned in the report of the committee which was reproduced in MaraT, Découvertes (see note 12).

${ }^{28}$ It has to be remarked that the effect was significantly more sensitive than in case of the hot bodies placed into the light cone. Whilst it was possible without difficulty to see the effect it turned out to be too faint to take a picture. 
special skills of the experimenter nor particular requirements regarding the weather conditions were necessary. Even with some clouds in the skies the experiments could be carried out successfully, contrary to the optical experiments. Here, a perfectly blue sky turned out to be necessary in order to produce the effects described by Marat ${ }^{29}$.

\section{Marat's electrical researches}

In 1782 Marat published his next monograph, a lengthy treatise on electricity describing some 200 experiments ${ }^{30}$. Among them were several in which he used the helioscope to visualise the electric fluid, to manipulate it and to compare it with the 'fluide igné' (see Fig. 7) ${ }^{31}$.

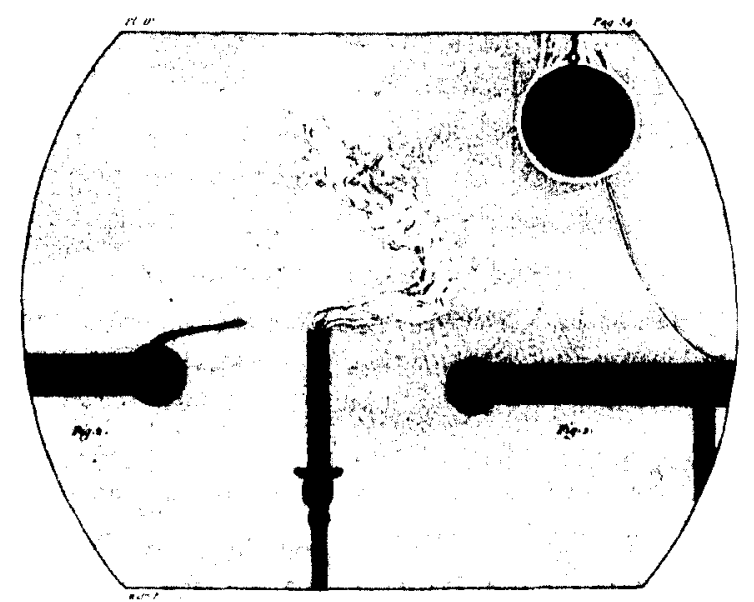

Fig. 7: Representation of the shadow projections of the electric fluid emanating from the prime conductor towards a candle (left) and to a red hot sphere (right). Plate published in Jean Paul Marat,

Recherches Physiques sur le Feu (Paris, 1780), courtesy of the Bakken Library Minneapolis, MN

${ }^{29}$ Several of Marat's optical experiments were analysed by Sonja Woltzen, my analysis of these experiments benefited significantly from her work (see Sonja WOLTZEN, Jean Paul Marats Experimente zur Farbentstehung: Nachbau einiger Instrumente, Nachvollzug ausgewahlier Experimente und physikalische Diskussion, unpublished thesis (Oldenburg 2000). For a more detailed discussion of the optical experiments see Peter HEERING, 'Analysing Experiments with Two Non-canonical Devices: Jean Paul Marat's Helioscope and Perméometre', Bulletin of the Scientific Instrument Society 74 (2000), pp. 8-15.

${ }^{30}$ Jean Paul MARAT, Recherches Physiques sur l'Électricité (Paris, 1782).

${ }^{31}$ Actually this image had already been published in the 1780 memoir on heat, however, Marat took up this topic once more in this $\mathbf{1 7 8 2}$ memoir on electricity. 
However, the helioscope had lost the dominant role it had in the first three publications. Marat described many other apparatus he claimed to have developed for his experiments, some of them being modifications of standard instruments in electrical experiments, whilst others were newly created. Some of the latter -at least according to Marat's claim- were displayed on a copper plate (see Fig. 8).

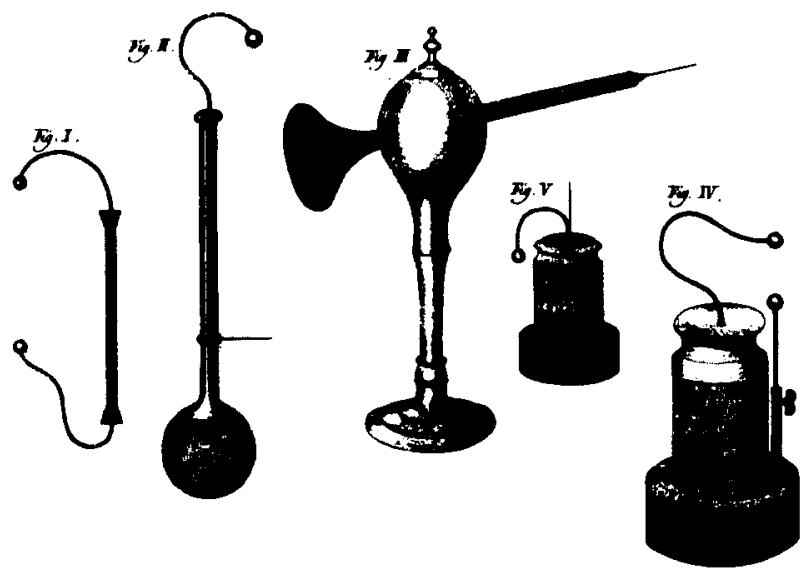

Fig. 8: Some of the devices Marat described for his electrical researches.

Plate published in Jean Paul Marat, Recherches Physiques sur l'Électricité (Paris, 1782), courtesy of the Bakken Library Minneapolis, MN

Three of these five instruments can be taken as being modifications of a Leyden jar (Fig. II, IV and V) which should serve as electrometers in Marat's experiments. In this paper I will concentrate my discussion on the experiments carried out with the two other items, one being a modified discharger (Fig. I), the other being an instrument Marat named 'perméomètre'. Contrary to the other devices shown on this copperplate I do not know whether any comparable instrument existed before Marat published its description (and likewise I do not know of any similar apparatus afterwards).

\section{Marat's experiments with dischargers}

Dischargers were very common in the second half of the $18^{\text {th }}$ century, they were used in experiments with Leyden jars in order to make the discharge controllable. Consequently, dischargers could be found in most instrument makers' catalogues. The ones Marat described were unusual in two respects: The standard dischargers had an insulating handle which was made from glass, 
Marat's did not. Moreover, dischargers normally consisted of a metal cylinder or wire with two metallic rods terminating in metallic spheres. The central cylinder in some of Marat's dischargers was a glass tube and the metal rods terminated close to the end of the cylinder. This design was the result of Marat's intentions: He wanted to use these devices in order to determine whether different substances defer ${ }^{32}$ the passage of the electric fluid or not. Thus, the cylinder could be filled either with liquids or with powders. To decide whether a substance permitted the passage of the electrical fluid the device was used to discharge a Leyden jar. Marat's classification of the substance's ability to defer the passage of the electrical fluid was based on the visual effect of the discharge: A bright white spark (as with metals, acids or salty water) indicated that the passage was almost free. A smaller reddish spark (as with red wine or milk) meant that the substance was deferring the passage significantly, whereas no spark meant the material was not allowing the passage of the fluid. Although this kind of determination initially seemed unfamiliar to me, yet the redoing of the experiments made it clear that this way of establishing a ranking between different materials is actually very convincing. The visual appearance of the different sparks can easily be distinguished, moreover, the idea of attributing more electrical fluid to the bright white spark than to the red one is persuasive. One aspect seems to be remarkable at this stage of the analysis of Marat's experiments: As in the experiments on heat and light Marat again relied on visual effects in order to determine the material properties. In this respect Marat's experiments are to be distinguished from others in which dischargers were used that seemed to be similar to Marat's on the first look; devices that were described by Edward Delaval and Tiberius Cavallo ${ }^{33}$. However, Delaval was attempting to determine whether the tubes broke from the discharge, Cavallo tried to feel the shock.

32 In Marat's theory, materials played a very important role in respect to electrical discharges; this also resulted in a significant language: To Marat, materials were not (active) conductors of the electrical fluid but the fluid was moving and the substances offered some kind of resistance to this motion. This resistance depended on the nature of the substance as well as on the amount. As a consequence Marat refused the use of the terms 'conductor' and 'non-conductor' and proposed to use the terms 'deferring' and 'not-deferring' substances. He made very clear in this context that these categories are not to be understood in absolute terms but that most materials differ gradually in their ability to defer the passage of the electrical fluid, see Marat, Electricite (ref. 30), p. 64.

${ }^{33}$ Edward Delaval, 'A letter ... containing some electrical experiments and observations', Philosophical Transactions of the Royal Society of London, 51 (1759), pp. 83-88, on Cavallo's device and his experiments see Paola Bertucci, 'Medical and animal electricity in the work of Tiberius Cavallo, 1780-1795', in Marco Bresadola and Giuliano PANCAldi (eds.), Luigi Galvani International Workshop. Proceedings (Bologna, 1999), 147-166, on 157. 
When discussing Marat's entire work on electricity the discharger is also prominent in a different context: In 1784 Marat published a second memoir in the field of electricity, this time, however, medical electricity. Marat's essay was designed to be an entry for the prize contest of the Academy of Sciences in Rouen, and actually he won. It does not seem too surprising that Marat turned to this field as he was a trained physician, however, in his 1782 monograph this field was only mentioned very briefly. In his essay Marat described 22 experiments, the only instrument that he had already described in his 1782 publication was the discharger. The experiments in this medical context were carried out in a very similar manner, this time organic material was used to fill the cylinder in order to determine (again from the colour of the spark) whether these materials were deferring the passage of the electrical fluid or not. The results were used to argue which parts of the body (and which diseases) could be treated by applying electrical shocks or discharges. ${ }^{34}$

Although Marat's discharger can be taken to be a modification of a standard device in electrical research, Marat himself claimed to be its inventor. He made similar claims in respect to several instruments which can be questioned as well. Actually there is one device which seems to be completely new, the perméomètre.

\section{The 'perméomètre'}

This instrument consists of a glass phial which is inserted into a metallic stand. The phial had a diameter of some 4 inches, its bottom being flat and the outside covered with tin foil. An iron rod which terminates in points is inserted into the phial and ends only some $13 \mathrm{~mm}$ from the glass bottom of the phial. The other end is clearly outside the neck of the phial. The neck of the phial was cemented into a hollow metal sphere which is to be filled with salty water. The sphere forms part of the stand of the perméomètre, this stand being entirely metallic and is to be carefully earthed at the beginning of the experiment.

${ }^{34}$ Marat made very clear - like in his 1782 work on static electricity - that the electrical fluid only acts when in motion. From this conceptual frame medical baths were rejected by Marat as a remedy, and he strongly attacked the proponents of these therapies, namely Bertholon and Sans (on Marat's work on medical electricity and these controversies see Peter HEERING: 'Jean Paul Marat: medical electricity between natural philosophy and revolutionary politics', in: P. BerTUCCI, G. PANCAldI (eds.), Electric bodies. Episodes in the history of medical electricity, Bologna, Studies in the History of Science 9, Bologna, CIS 2001, pp. 91-115. 
The experiment is carried out in a darkened chamber. The whole instrument is placed close to the prime conductor of an electrostatic generator, the bottom of the phial facing the conductor. The conductor is charged and - according to Marat- some luminous appearances are to be seen as depicted on the plate (see Fig. 9). Even after carefully reading Marat's description of the effects I was not sure of having properly understood what should happen - and certainly not why. Some additional remarks Marat made did not help to develop a better understanding. Marat spoke of the necessity of covering the bottom of the phial with tin foil in order to minimise the "kind of gleaming sun ${ }^{35}$ which should be generated from the electrical stream coming from the prime conductor. Otherwise this effect would prevent to identify the phenomenon that was to be observed at the pointed end of the rod inside the phial.

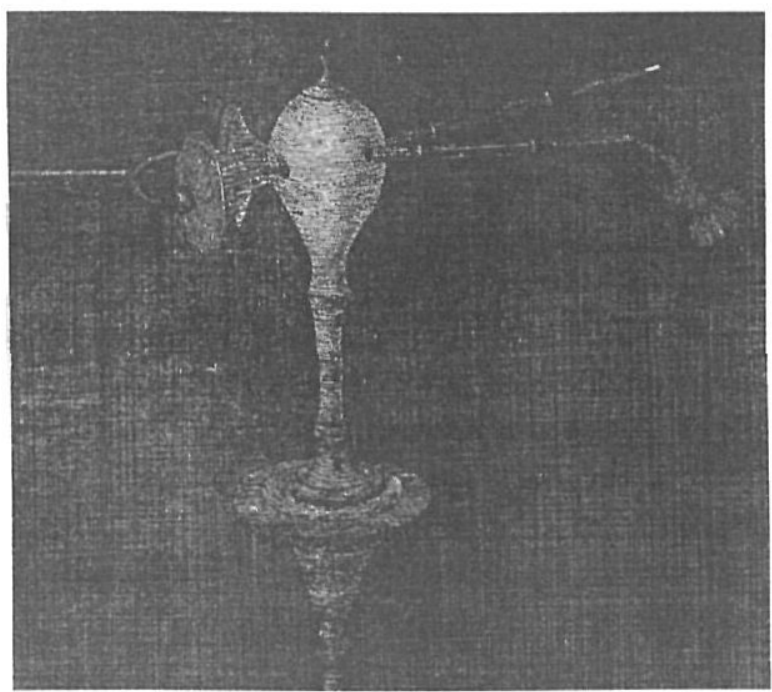

Fig. 9 Experiments with the a modified perméomètre, in the metal stand are two glass phials inserted. Plate published in Jean Paul Marat, Recherches Physiques sur l'Électricité (Paris, 1782), courtesy of the Bakken Library Minneapolis, MN

Basically the conceptual idea of this experiment can be taken to be comparable to the ones carried out with the discharger: Marat was attempting to demonstrate that different types of glass did not defer the passage of the electrical fluid. According to his argumentation, which seems to be very convincing, it was necessary to show

${ }^{35}$ Marat, Électricité (note 30), p. 92. 
that the outer point of the rod was charged. As the metal sphere is entirely filled with water and the whole stand is earthed carefully, this arrangement would prevent any electrical fluid from creeping over the outer surface of the phial towards this end of the rod. Consequently any charge that could be found on the rod must have passed from the outside tinfoil through the glass onto the rod.

When attempting to rebuild the perméomètre (Fig. 10) we had to face the problem that this was neither a successful instrument nor a modification of a standard device such as in the case of the helioscope. Marat's description was very vague in several respects, in particular with regard to the metal stand. However, this is explicable, as the stand is only a support for the important part of the device - the phial - so it does not need a specific description. I decided that the stand should be made of brass, basically because this was one of the metals which had been used to produce devices for electrical experiments. The glass sphere turned out to be problematic: Marat was very specific in respect to the glass he used: "flingt-glass, de verre chrystallin, de pirette, de chambourin, ou de verre à bouteilles" ${ }^{36}$. Unfortunately these materials were not available to our glass blower. In order to be able to carry out the experiment I decided to start with a phial made from a modern material which had not been available to Marat. At this point one might question whether it was justifiable to use 'modern' glass. However the motivation to work with the instrument was not to check Marat's experimental findings but to develop an understanding of the experiment as well as the observations that might have been possible. As a consequence it is crucial to connect the experiences and observations made in the laboratory with the available source material. Under these circumstances it seems to be acceptable to use a 'modern' material.

${ }^{36}$ Marat, Electricité (note 30), p. 95. Marat specified that 'verre de chrystallin' was fine white glass, 'pirette' ordinary white glass and 'chambourin' ordinary green glass. 


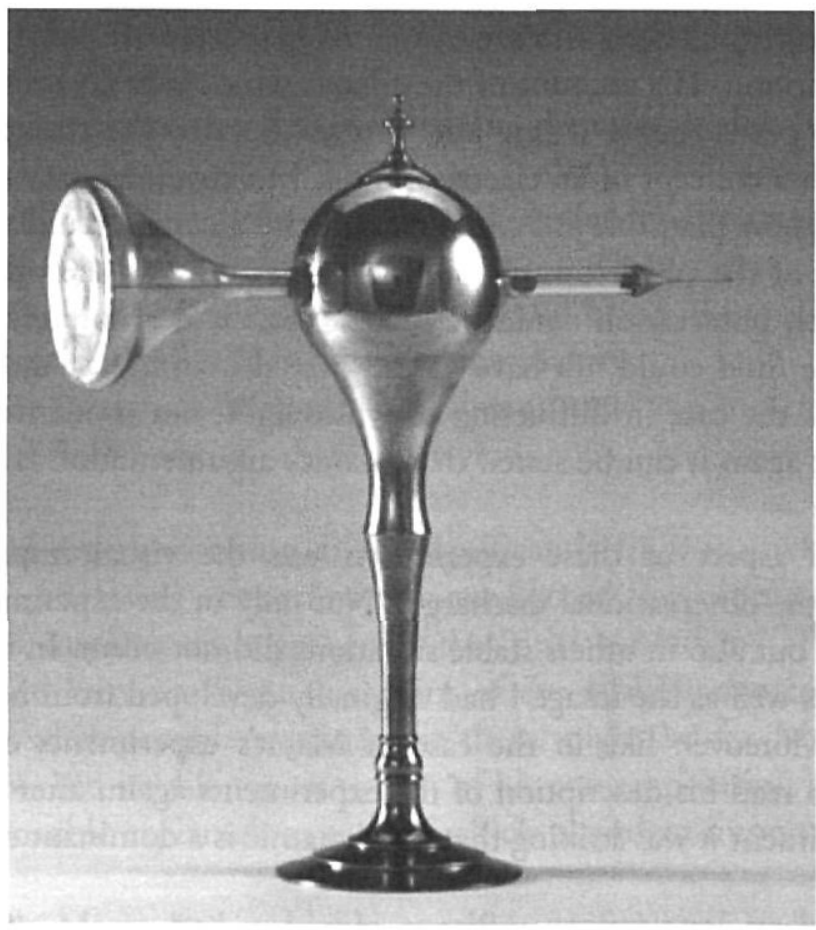

Fig. 10: Reconstruction of the perméomètre..

Photo W. Knust, courtesy of the museum 'Mensch und Natur' Oldenburg.

The perméomètre was placed close to the conductor of a reconstructed electrostatic generator, the room was darkened, the axis of the wheel was turned and I saw ... - nothing. I changed to a stronger machine, turned the axis and again I did not see anything. Finally I started to work with a small van der Graaf generator, this being the most powerful device in our department for the production of static electricity. Very quickly small sparks could be observed between the prime conductor of the generator and the tin foil at the bottom of the phial. After several minutes some greenish light could be seen creeping over the phial from the tin foil towards the brass stand. At about that time little sparks could also be seen between the inner end of the rod and the bottom of the phial. A few minutes later a greenish light could also be seen forming expanding circles, starting from the middle of the bottom of the phial. I was still not able to see any luminous appearance at the end of the rod outside the phial. However, a small spark could be seen and felt when a finger was brought close to this end. 
Having seen the effects the experiment was comprehensible to me - as was Marat's description. His account of the effects, which initially seemed so strange to me, made perfect sense if one attempts to describe the surface discharges I observed with a concept of an electrical fluid. Moreover, Marat's argumentation became even more plausible as I could observe the 'electrical fluid' moving on the outer surface of the phial towards the metallic stand. On the other side of the stand, no such observation could be made. Thus it is absolutely reasonable to argue that the fluid could not have passed over the surface of the phial towards the rod. As is the case in diffraction of white light, our modern explanation is different, but again it can be stated that Marat's argumentation is consistent.

A central aspect of these experiments was the visual impression of the dynamics in the observational discharges. Not only in the experiments described here in detail but also in others stable situations did not occur. In this respect the copperplate as well as the image I had originally developed from Marat's text was misleading. Moreover, like in the case of Marat's experiments on heat it was remarkable to read his description of the experiments again: after having carried out the experiment it was striking that the dynamic is a dominant characteristic ${ }^{37}$.

\section{Conclusion}

From analysing Marat's practice in the case of his electrical experiments the two characteristics that had already been identified in the analysis of the optical experiments could be found again. But they are not only asserted from the experiments carried out with the helioscope but also from those carried out with entirely different devices. Thus they can be taken to be an outcome of Marat's style of experimentation and not a result from using the helioscope $e^{38}$.

By way of a summary the following characteristics of Marat's style of experimentation could be formulated:

37 This raises of course questions in respect to the relation between Marat's public demonstrations and his written monographs. This aspect will be discussed in a forthcoming paper (Peter HeERING: 'Public experiments and their analysis with the replication method', paper presented at the conference 'From the itinerant lecturers of the 18th century to popularizing physics in the 21 st century - exploring the relationship between learning and entertainment', Pognana, June 2003).

38 I am using the concept of 'style of experimentation' as an expansion of Ludwik Fleck's epistemological system, for a brief description of this concept see HEERING, Grundgesetz (note 1). 
- The experiments are designed to visualise the imponderable fluids as well as their manipulation.

- The experiments are designed to be demonstrated in front of an audience.

- The results of the experiments are to be understood without any further theoretical assumptions ${ }^{39}$.

- The experiments focus on the electric fluid being in motion - no static situations can be found in Marat's experiments.

- The aim of the experiments is to demonstrate the 'real nature' of the electrical fluid and not only its behaviour.

This style of experimentation differs significantly from that which could be identified in analysing experiments conducted by some of Marat's contemporaries, in particular members of the Parisian Academy of Science such as Coulomb and Lavoisier ${ }^{40}$. At this point of the analysis one could raise the question as to what possible explanations there might be for Marat's style of experimentation and its differences to that of his contemporaries. I am going to discuss three possible explanations each of which played an important role.

First of all, Marat had a highly specific, professional background as a physician. Therefore one might conclude that his professional training might have had an influence on his style of experimentation. However, taking a closer look at Marat' medical practice this interpretation does not seem to be very likely: His practice as a physician did not comply closely with the standards of the $18^{\text {th }}$ century ${ }^{41}$. Therefore it is not very plausible to suppose that his training as a

${ }^{39}$ This can also be seen from very explicit claims Marat made: "... not a single hypothesis, not a single daring reasoning always the theory goes together with the experience, and everything is deduced rigorously from reliable facts from which I permit myself only to draw the immediate conclusions. Not only is every assertion based on reliable facts, for being true it is necessary that these facts are simple ..." Marat, Electricité (note 30), p. 23.

${ }^{40}$ On the style of experimentation of these scientists see HEERING, Grundgesetz (note 1).

41 Lemaire observed in analysing Marat's medical practice: "Consultations in the 18th century were very different from what they became in the 19th. They were practised at a distance. The doctor did not see the patient; he received a written account of the sick person's complaints and responded with a lengthy report, usually several pages long, ending with prescriptions. Marat's approach was significantly different. ... it is clear that he examined patients face to face" Jean-François LeMAIRE: 'Le Dr Jean-Paul Marat médecin parisien', in J.-F. LEMAIRE, J. P. PoIRIER (eds.): Marat homme de science?, (Paris 1993), 13-34, 22, translated in Clifford D. ConNER, Jean Paul Marat: Scientist and Revolutionary (Atlantic Highlands (New Jersey), 1997), 36f.. 
physician had an impact on his style of experimentation, on the contrary it would seem to be the other way round. This image also holds true when Marat's researches in the field of medical electricity are analysed: his style of experimentation is again in close conformity with the characteristics identified from his researches in natural philosophy but they are significantly different from researches in this field carried out by his contemporaries ${ }^{42}$.

A second relevant aspect could be Marat's political position. In analysing his political writings Mona Ozouf comes to the following characterisation: «Central to this language [of the Ami du Peuple, P.H.] was an obsession with visibility. For Marat the absolute evil was not so much the hostility of the counterrevolutionaries as the obstinacy of the people in not seeing it. The French were purblind: sometimes because the tinsel of "vanities" dazzled them, other times because they were asleep. The two besetting national sins were gullibility - the illusion of seeing where there was nothing to be seen - and lethargy - eeing nothing where vision was needed. ... Between the slumberers and the scoundrels there was only Marat, in the solitary role of the sentinel of the people, watchdog of the Revolution, who, while everyone else slept, tirelessly fingered the guilty. Only he saw clearly, ripped away the veils ... Marat was the eye of the people.) ${ }^{43}$

The importance of visualisation identified by Ozouf in Marat's political writings corresponds to his style of experimentation. The similarities between these two fields can be carried further: Marat placed himself in the position of the person who was clarifying things to his audience, in politics as well as in science. However, it was always the audience that had to see. Clarification is one of the central features of his scientific writings: "In working to set the true fundamentals in medical electricity I have started to remove defective agents which, after having confused the science, are misleading those who promote its ${ }^{44}$.

The correlation between Marat's style of experimentation and his political position during the French revolution can be broadened: Marat is not analysing (ref. 34)

${ }^{42}$ For an analysis of Marat's researches in medical electricity see HEERING, Medical Electricity

${ }^{43}$ M. Ozouf, 'Marat', in: F. FURET; M. Ozouf (eds.), A Critical Dictionary of the French Revolution (Cambridge (Mass.), 1989), pp. 244-251, on p. 249.

${ }^{44}$ Jean Paul Marat, Mémoire sur l'Électricité médicale, (Paris, 1784), p.80 
stable situations but (radical) changes, this holds for the emanating 'fluid igne' as well as for the electrical discharges.

Although this may sound convincing a third aspect should be taken into consideration: It is questionable whether French scientists are the appropriate reference frame for discussing Marat's style of experimentation. Marat had spent some ten years in Britain, moreover it is not clear whether he gained his medical training in England or in France. "Le médecin anglais' - as he was called in the suburb of St-Germain...." ${ }^{45}$ could also have possessed a style of experimentation corresponding to that of British natural philosophers. One implication of this interpretation would be that styles of experimentation are to be analysed in a national context. However it is obvious that this cannot be formulated in a general manner as Marat's experiments in the field of medical electricity differ significantly from those of his British contemporaries such as Tiberius Cavallo, John Birch, or Francis Lowndes ${ }^{46}$. Marat's style of experimentation seems to be comparable to the works English researchers (such as Joseph Priestley) published in the field of natural philosophy ${ }^{47}$.

From my understanding Marat's style of experimentation cannot be explained by any of these factors individually but that one has to take them all into consideration in order to understand the origins of his style. Likewise, Marat's style

${ }^{45}$ Marcel Borteux, 'Marat électricien', in Jean-François LeMAIRE, Jean Pierre POIRIER (eds.), Marat homme de science?' (Paris, 1993), 109-113, on 110.

46 Tiberius Cavallo, An Essay on the Theory and Practice of Medical Electricity, 1st Ed. (London 1780); John BIRCH, Considerations on the Efficacy of Electricity, in removing female Obstructions, to which are annexed cases with remarks, (London 1779); Francis LOWNDES, Observations on Medical Electricity: Containing a Synopsis of all the Diseases in which Electricity has been recommended or applied with Success; likewise, Pointing out a new and more efficacious Method of applying this Remedy, by Electrical Vibrations, (London 1787).

${ }^{47}$ These similarities are not limited to experiments with dischargers. Priestley also described experiments in which animals were electrocuted and which are very similar to the ones Marat described in his 1784 monograph on medical electricity (see Joseph PRIESTLEY, The History and Present State of Electricity, (London, 1775)). However from Priestley's publication it is unclear whether the motivation for Priestley's researches can be seen in a medical context or not. The similarities can be expanded if some of Priestley's earlier experiments on electrical phenomena are analysed (see i.e. Joseph PRIESTLEY, 'Experiments on the lateral Force of Electrical Explosions', in: Philosophical Transactions of the Royal Society 59, (London, 1769), pp. 57 - 62). This will be subject of further study. However, in discussing Marat's style of experimentation in relation to his political position it seems remarkable that Joseph Priestley can also be taken as being an advocate of the political ideas of the French Revolution. 
of experimentation was probably not the only reason the members of the Academy had for rejecting his work - but it surely played an important role.

\section{Acknowledgements}

I am indebted to Jan Deiman (Utrecht Universiteitsmuseum) who made possible the examination of the solar microscope for the purpose of reconstructing the helioscope. I took the measurements of the original instrument together with Sonja Woltzen, Anke Wachtmeester and Hans Holtorf, the latter also made the technical drawings for the workshop. The major parts of the helioscope were built by Andreas Ewert and Jessica Hespe-Meyer. The technical drawings for the reconstruction of the perméomètre were made by Heinz Böttcher and Jens Köppen, the metal parts of the instrument were manufactured by Renke Logemann and Olaf Seifert, Silvia Goldmann made the glass phial. Falk Rieß made valuable comments from which this paper benefited significantly. 